\title{
Os possíveis significados da Filosofia nas séries iniciais
}

Patrícia Peregrino Montenegro (1)

Resumo: O trabalho com Filosofia nas séries iniciais se apresenta como um desafio para os diversos atores do contexto escolar. O texto expõe o caminhar do projeto Filosofia na Escola da Universidade de Brasília e procura refletir sobre seus inúmeros significados. A prática da filosofia com crianças como espaço de construção plural, multidisciplinar e de reflexão constante atravessa as reflexões do texto que também procura pensar os desafios e propostas que se descortinam nesse encontro com o pensar que passa a acontecer na Escola Classe 06 de Planaltina.

Não há coisa alguma que persista em todo o universo. Tudo flui, e tudo se apresenta numa imagem passageira. O próprio tempo passa com um movimento contínuo, como um rio... O que foi antes já não é, o que não tinha sido é, e todo instante é uma coisa nova. (...) Também nossos corpos mudam sempre e sem descanso... E também a Natureza não descansa e, renovadora, encontra outras formas nas formas das coisas. Nada morre no vasto mundo, mas tudo assume aspectos novos e variados... Todos os seres têm sua origem noutros seres. (Ovídio)

\section{Os significados da filosofia e sua prática nas séries iniciais}

A prática da filosofia com crianças tem relevante significado dentro da escola por permitir um encontro frutífero de vários sujeitos, de vários saberes, da construção coletiva e individual desses saberes. Sua importância maior está na construção de um espaço multidisciplinar e plural constituinte e constituído por sujeitos interessados numa educação mais humanizante, menos mecânica, mais eficaz no sentido da construção do pensar. Dentro desta perspectiva temos buscado criar condições para que esse espaço para o pensar seja empregado dentro da sala de aula, com as crianças, que são nosso maior objeto de preocupação enquanto docentes. Não obstante, é muito difícil, na prática, transformar nosso objeto de preocupação, as crianças, em sujeitos ativos aos nossos próprios olhos. Isso porque nossa formação, deficitária na percepção de sujeitos, é o maior empecilho dentro desse processo. Os caminhos contrários a esse novo que fazer, dentro do ambiente escolar, são muitos, esbarram freqüentemente em dificuldades físicas, organizacionais e temporais da estrutura da própria escola. Adentrar esse caminho pressupõe uma estrada de desconstrução de valores por muito tempo cultivados, já sedimentados e incorporados no dia-a-dia da sala de aula.

O apoio do projeto Filosofia na Escola da Universidade de Brasília, dentro desse contexto, tem constituído importante ferramental, possibilitando uma ampla reflexão da práxis pedagógica, da relação professor/aluno e de uma elaboração crítico-reflexiva sobre o papel desses dois sujeitos. Optamos por esse caminho por 
acreditar no impacto positivo causado aos alunos pela prática filosófica, na construção de uma postura reflexiva diante de sua realidade, da escola e de si mesmos. Cremos também nesse processo de construção coletiva como um lugar onde não apenas nossoscorpos mudam sempre e sem descanso, mas também nossas mentes, num movimento contínuo, como o do rio citado por Ovídio na epígrafe, possibilitando uma educação não-ortodoxa que se abra à experimentação responsável, que assuma novos e variados aspectos, aonde seres criem e recriemse, num movimento tão plural quanto o é o próprio ser humano.

Procurarei, partindo da realidade posta, mergulhar numa reflexão acerca desse escopo. Numa reflexão que toma como espaço central a escola, lócus de desenvolvimento do projeto, sua estrutura e organização. Tentarei ponderar sobre o impacto da filosofia nos sujeitos constituintes da escola, em especial dos educadores e educandos envolvidos nessa prática. Quais são as contribuições da filosofia para a prática educativa? O que representa o planejamento dentro desse processo? Qual é o espaço que a filosofia ocupa na escola, na sala de aula e na reflexão docente? Como ela é vista pelos alunos? Como é vista pelos professores? Quais as razões que levaram a escola e os professores a desenvolverem-na?

\section{A Escola Classe 06 de Planaltina - sua caracterização e inserção dentro do projeto}

O projeto é multifacetado e flexível, as escolas não são obrigadas a adaptar-se a ele. Ele assume várias formas, uma de suas características é a multiplicidade e o respeito aos espaços que ocupa, não um respeito de acomodação, mas um respeito de identidade, de entendimento da diversidade de realidade das escolas. Os pressupostos do projeto são mantidos, mas de acordo com seu lócus de execução ele pode assumir uma dinâmica nova distinta das já existentes. Uma característica fundamental inerente a ele é a experimentação, podemos buscar coletivamente, ou mesmo individualmente, caminhos que possam favorecer $e$ ampliar os espaços de preocupação com o pensar.

Como disse que ele assume diversas formas de acordo com o lugar em que atua, antes de continuar gostaria de apresentar um dos espaços em que funciona, o espaço da minha prática no projeto, a Escola Classe 06 de Planaltina.

A Escola Classe 06 de Planaltina está situada numa cidade satélite do Distrito Federal, que tem em seu quotidiano problemas sociais sérios como a violência, diariamente vivenciada por seus alunos nas mais diversas formas: violência física, verbal, moral, social. Essa violência tem permeado o projeto ao longo de sua história em nossa escola e é visível na fala das crianças. Outra realidade fortemente presente na escola é carência financeira. A maior parte das crianças provém de uma classe econômica não abastada, não são raros os exemplos de crianças chegando à escola no início do dia letivo e perguntando pelo lanche. Essa realidade econômica difícil gera outras carências além da alimentar, entre elas a carência cultural e o pouco, ou nenhum, acesso a atividades como cinema, teatro, passeios. Muitos de nossos alunos sequer saíram de Planaltina algum dia. 
A escola atende a três modalidades de ensino, a saber: ensino fundamental (séries iniciais, $1^{\mathrm{a}}$ a $4^{\mathrm{a}}$ séries), educação infantil (alunos com seis anos completos ou a completar até 31 de junho, provenientes do lar, projeto do governo local 'Quanto mais cedo melhor') e ensino especial (alunos com deficiência mental). São 862 alunos organizados em 26 turmas e distribuídos em dois turnos de cinco horas de aula: matutino - 7:30 às 12:30h e vespertino - 12:30 às 17:30h. A escola não funciona no noturno.

Está localizada na entrequadra 5/6 do Setor Residencial Leste de Planaltina, popularmente conhecido como Vila Buritis.

A escola emprega 51 funcionários: 30 professores e 21 servidores. Dos trinta professores, três atuam na direção da escola, composta por diretor, vice-diretor $e$ assistente pedagógico, um está na coordenação pedagógica e vinte e seis estão em regência de classe. Entre os vinte e um servidores da carreira de assistência à educação temos dois funcionários de natureza administrativa atuando na secretaria da escola para manter o registro dos alunos (matrícula, histórico escolar, diários de classe), quatro vigias, três porteiras, duas merendeiras, seis funcionários da limpeza e quatro funcionárias realizando serviços gerais. A carência está principalmente nas merendeiras que deveriam ser por modulação (2) quatro e nos servidores da limpeza que deveriam ser no mínimo dez.

As atividades pedagógicas dos professores englobam regência (vinte e cinco horas semanais), reforço escolar (em horário contrário), planejamento, elaboração de material, entre outras. É feito um planejamento quinzenal de atividades, às segundas-feiras, levando-se em conta as habilidades previstas no currículo_(3), o projeto Político e Pedagógico da escola e os projetos especiais, entre os quais estão os projetos do meio ambiente, que possui textos voltados à reflexão das ações do homem no meio ambiente, através dos quais os alunos são alfabetizados e o projeto de extensão da Universidade de Brasília, Filosofia na Escola, desenvolvido desde o início do ano letivo de 2003.

Politicamente a escola está organizada dentro de uma hierarquia: a escola deve seguir as orientações gerais, as normas e os projetos estabelecidos pela Secretaria de Educação do Distrito Federal e pelo Conselho de Educação. Estes são representados nas cidades satélites pelas Gerências Regionais de Ensino e nas escolas a responsabilidade pela aplicação destas normas é da direção. A direção hoje é indicada pelo Governo do Distrito Federal e deve administrar a escola juntamente com o Conselho Escolar, eleito e composto por todos os segmentos da comunidade escolar, professores, servidores, pais e alunos. No caso da escola não há alunos no Conselho, pois não há alunos com mais de catorze anos, exigência para sua participação, sendo representados pelos pais. Contudo, dentro dessa estrutura política há nas escolas um espaço para que estas busquem uma feição $e$ identidades próprias, que atendam às necessidades reais da comunidade da qual participam, que está assegurado no próprio currículo: "Cada escola, mesmo pertencendo a um sistema público, precisa ostentar feição própria, desenvolver projetos que atendam às necessidades específicas de seus alunos, voltar-se para a comunidade, onde se insere, e acompanhar os avanços científico-tecnológicos". (4) 
É dentro desse espaço que a escola optou através da direção e dos professores pelo desenvolvimento do projeto Filosofia na Escola.

\section{O significado da prática filosófica para a escola enquanto instituição}

O projeto entrou na escola através de um convite da professora Juliana Merçon, então coordenadora do projeto, pois para o ano de 2003 não havia nenhuma escola de $1^{\mathrm{a}}$ a $4^{\mathrm{a}}$ série envolvida no projeto. Essa oportunidade aconteceu porque a essa época eu já estava trabalhando na direção da escola, era aluna da professora Juliana e estava envolvida com uma atividade de conhecimento do projeto através da disciplina Projeto 1 (5). Uma das orientações da professora Juliana foi a recomendação de que a participação dos professores no projeto deveria ser voluntária e não uma imposição. Haveria um curso de formação para o trabalho da filosofia em sala de aula e uma parte da vaga desse curso seria reservada para os professores que quisessem aplicá-lo na escola.

No início do ano letivo de 2003, fiz a proposta ao grupo de professores e inicialmente 16 dos 30 professores da escola, incluindo os três membros da direção, resolveram fazer o curso de formação. O objetivo exposto foi o de que trabalhar filosofia com crianças despertaria o senso crítico destas, as faria melhorar nos aspectos cognitivos trabalhados na escola em geral, ajudaria a libertá-las do senso comum e nos ajudaria, enquanto professores, a despertar essa curiosidade pelo saber nos alunos e fortaleceria nossa práxis pedagógica dentro do que hoje se chama de educação para o pensar. Atrás dessa possibilidade, começamos a fazer o curso com uma carga horária inicial de 40 (quarenta) horas, planejado de forma a oportunizar um conhecimento teórico-prático que nos levasse a poder trabalhar na sala de aula com as crianças. No início do curso na UnB, realizado de segunda a sexta-feira, das 19:00 às 23:00h, houve um grande choque cultural para os professores, pois nele não eram dadas formas de aplicação da filosofia com crianças, eram feitas reflexões e oficinas relacionadas ao pensar filosófico com os próprios professores, que não estavam acostumados a esse tipo de prática. Foram muitos questionamentos sem resposta, prática muito diversa daquela que estávamos acostumados dentro de um modelo educacional com o objetivo centrado na busca da resposta correta. O curso possibilitou-nos realizar oficinas do perguntar, desenvolver o questionamento filosófico dentro de nós. Saímos dele sem muitas respostas de como trabalhar a filosofia na sala de aula e isso muito nos angustiava.

Os trabalhos na escola começaram duas semanas após o curso inicial e se dariam todas às quintas-feiras com atividades de planejamento e execução das oficinas. $\mathrm{O}$ planejamento e execução dessas oficinas se dava com a presença da professora Juliana Merçon, das professoras regentes cursistas e dos mediadores da UnB em reuniões semanais para planejamento e avaliação das atividades em sala de aula, com a execução do planejamento pelo professor da turma e mediadores da UnB. Os mediadores são estudantes do curso de Pedagogia que se interessam, dentre os diversos caminhos a escolher, por sua inserção na prática pedagógico-filosófica, 
escolhem o caminho da educação para o pensar como prática. O estabelecimento da dupla professor regente/mediador constitui um equilíbrio entre a teoria, vista pelo mediador em disciplinas e a experiência de sala de aula que o professor traz.

Inicialmente houve muita divergência de opiniões, grupos muito distintos, principalmente em objetivos (estágio, graduação, curso de extensão), que não estavam conseguindo encontrar um ponto comum, que a meu ver era claro: a própria ação nos unia na busca pela prática filosófica. Uma busca que é muito distinta de um para o outro, mas que também se faz nessa dessemelhança, no auscultar do pensamento tão díspar ao meu, que me apresenta uma idéia sobre um mesmo assunto vista sob outro prisma, sob outra maneira de pensar. Esse é um dos aspectos mais apaixonantes da proposta do projeto: a coexistência de visões tão diferentes, por vezes antagônicas, acerca de um mesmo assunto. Um refletir distinto do meu, mas que não o invalida, antes o enriquece, o confronta, me obriga a continuar refletindo a investigar, a repensar, a relação dinâmica que esse esforço conjunto do pensar proporciona.

Tomando emprestadas as palavras do poeta Ovídio, “... Nada morre no vasto mundo, mas tudo assume aspectos novos e variados..." eu, a cada encontro do curso, sentia-me assim, assumindo um novo aspecto enquanto meu pensamento assumia novas formas.

O que no início parecia um empecilho, a diversidade do grupo, sua própria heterogeneidade, foi sua maior contribuição no transcorrer das atividades, pois enriqueceu as visões. A diversidade enriquece, multiplica, fertiliza. Aprender a conviver e a respeitar esta sem impor sua própria visão é, para mim, um dos objetivos da investigação filosófica. Percebi um crescimento no grupo de docentes que levou o projeto a frente na escola, um amadurecimento que levou-nos ao debate constante, à troca de experiências, ao respeito à diversidade que há muito não se via no grupo. Um interesse na investigação, na busca de técnicas que favorecessem o pensar na sala de aula, um interesse no diálogo e na escuta do outro.

Acho que o construir coletivo do curso, a divisão de responsabilidades entre todos também é tarefa muito enriquecedora. Estamos muito acostumados a receber programas prontos a criticá-los ou aceitá-los. Construir coletivamente torna-se uma dificuldade. A partir, daí parece que o processo deslanchou, o curso começou a se moldar por seus participantes, os diversos interesses foram aparecendo e se mostrando. As inquietações eram e continuam sendo muitas, acho que praticar a filosofia é estar disposto a rever sempre nossos conceitos, é um buscar incessante da reflexão, reflexão que não é fácil, que por vezes nos tira o norte.

Para a escola o curso se apresenta como ferramenta necessária nessa busca pela filosofia como instrumento na ação pedagógica. Ele viabiliza um espaço de reflexão coletiva, de busca, de investigação, de experimentação, tem cumprido o seu objetivo tanto na construção coletiva da filosofia e do pensar e investigar coletivo. 


\section{Os significados do projeto para os docentes}

O projeto mudou a dinâmica da escola e o quotidiano dos alunos e professores. Em muitas salas extrapolou o horário da quinta-feira e começou a buscar outros espaços. Em outras continua restrito às quintas, dependendo do envolvimento do professor com o projeto. Gosto muito de citar o exemplo da professora Geraldina Elias Bonfim e de sua turma que, tanto no ano de 2003 como no ano de 2004, têm fornecido relatos de experiências muito positivas em relação ao projeto. Relatos de desenvolvimento surpreendente do raciocínio lógico da turma, desenvolvimento da oralidade, da fala crítica, do questionamento. O projeto representa a possibilidade de cultivar a curiosidade e a investigação pelo saber, um espaço de reflexão não só para crianças, mas para nós mesmos. A filosofia ensina a prática da escuta, ensina a reflexão crítica da nossa própria prática, pois percebemos que essa construção coletiva peculiar ao projeto nos enriquece. Uma prática que não pode ser isolada, mas coletiva para que não acabemos na recorrente prática da imposição de nossos próprios pensares. Na imposição de nossos valores àqueles que certamente encontram-se sob nossa tutela, para que não continuemos a imprimir os nossos quereres.

A prática do projeto de filosofia na escola $e$ o desenvolvimento das habilidades necessárias à sua execução tem nos ajudado a aceitar a infância, a não manipulála, ouvir as crianças, seus raciocínios, seus pontos de vista. Conhecê-las sem ter a prepotência de querer transformá-las, moldá-las, como se tem feito ao longo de tantas gerações, prática da qual nós mesmos somos produtos. O projeto tem devolvido nossa capacidade de nos surpreender, de conhecer um pouco a infância e de ouvir a sua voz: "Ser novo por dentro é ser inteligente, perguntar, ler, escrever, estudar bastante e depois de velho ainda ficar novo e continuar aprendendo". (6Nos faz também despertar para tristes realidades: "Sinto raiva de ser criança porque vejo a minha mãe sofrendo e não posso fazer nada" (7)

Trabalhar filosofia com crianças é planejar condições propícias para o seu exercício, é não tolher essa curiosidade natural que há na criança, é perpetuar a fase dos "porquês" que geralmente a família através dos pais e a escola através de seus professores sufoca. É esse o nosso grande desafio em sala de aula: não nos entregar à armadilha de perpetuar a educação do costume, não ajudar a fabricar marionetes, não aceitar a cômoda benevolência de dar aos nossos alunos respostas prontas. É inserir o aluno dentro da prática do raciocínio, onde existam situações favorecedoras de diálogo reflexivo. Um ensino voltado para a reflexão, para o movimento em que o pensamento volta-se para si mesmo, onde o educando interroga-se, busca-se, identifica-se, onde o educador também possa experimentar esse movimento reflexivo, onde ele possa ser mestre-aprendiz e o aluno aprendizmestre. Esse caminho é fácil? Com certeza não. Possível? Acreditamos que sim, mas o seu percorrer é muito doloroso, pois implica no desmoronamento de muitas conviç̧ões que carregamos ao longo de toda uma formação deficitária. A prática da filosofia, não só com as crianças como também com os pares, servirá de elã na reconstrução dos desmoronamentos conceituais que ela própria acarreta. É preciso para tal prática um redimensionamento da atividade docente, um esforço contínuo e coletivo pela busca filosófica. Faz-se necessária uma reorganização do espaço 
escolar, o esforço para a prática da escuta por parte do professor, já tão habituado a falar, abafando a voz dos alunos. É dispor de interesse pela leitura, pelo preparo, pela discussão. É preciso aprender a se deparar com o insólito, habituar-se a não ter as rédeas do jogo, cada aula pode levar a um rumo desconhecido, é preciso aprender a lidar com a angústia de não ter o domínio do que vai acontecer, nesse desconhecido reside a oportunidade de experimentação e de crescimento, está inserido no desconhecido, no inesperado, a grande mola propulsora do pensar:

O pensar é um encontro. Todo encontro que se aprecie como tal não pode ser antecipado, deduzido ou previsto em formato que possa ser utilizado para fins didáticos. É o choque do imprevisto que nos obriga a pensar, que nos comove inteiramente, que nos deixa perplexos, que nos leva a problematizarmo-nos, a pensar o que até agora não podíamos pensar. (Kohan, 2003, p. 232)

Não se pode prever o que será dito, não se pode pensar antecipadamente os caminhos da discussão, o que será investigado, o que se tornará problema. Nesse caminho reside a busca coletiva, a preparação para o imprevisto e para a contestação. Precisamos aprender essa ruptura com a repetição, com a segurança do que se sabe, do que se diz, do que se ouve. Podemos nos tornar o objeto de contestação, ouvir as críticas que se voltam à nossa prática docente, não é fácil aceitar essa contestação. É preciso ter grande maturidade na busca dessa aceitação, alicerces abalam-se dentro de nós. É por tudo isso que a professora Bernadina Leal afirma: "Filosofar com crianças requer uma grande disposição em rever constantemente a prática escolar cotidiana". (Leal, 2000, p.88) Filosofar com crianças requer um grande esforço em nossa formação continuada, na busca por elementos que subsidiem a prática, na busca de espaços para a própria prática. Precisamos deslocar esforços para aprimorar nossas habilidades, refletir sobre nossas posturas. Exige de nós a habilidade de inquietar-nos com o costume. Exige, em alguma medida, a busca pela prática da própria infância para melhor entendêla. Exige a habilidade de saber problematizar, de indagar a fundo as questões, de saber mediar as aulas para que estas revelem reflexão e que não sejam apenas oficinas de relatos de experiências, onde o aluno aproveite a oportunidade para contar suas histórias cotidianas. É preciso saber problematizar essas experiências. Favorecer atitudes questionadoras, propiciar o movimento de idéias. Problematizar a si mesmo. É preciso emancipar as inteligências, libertar o pensamento, fazê-lo fluir.

A prática da investigação entre o grupo de professores e mediadores no planejamento significa muitas vezes se expor e essa exposição sempre tem um retorno crítico. Acostumar-se a ele não é tarefa fácil, parece um grande entrave para o grupo no processo. Às vezes penso que esse é um dos valores que o silêncio tem no projeto: o medo de expor-se, o medo das críticas. Parece que o falar-se, o expressar-se, o visualizar-se, o avaliar-se, tem sido esquecido ou abandonado pelo grupo docente. O projeto incita a busca desse refletir, desse falar, mas os professores têm medo da exposição. Essa busca do levar às oficinas de filosofia espaços para o pensar, espaços para que muitas vozes ecoem dentro da sala, espaços para várias reflexões, reflexões sobre o mundo, a vida, a morte. Todo esse conjunto de ações exige do docente um esforço no sentido do próprio preparo: 
"precisa-se antes de tudo de um docente comprometido com sua atividade, capaz de suscitar em seus alunos um entusiasmo que ele já possui; de outro modo, a proposta fracassa" (Waksman, 2000, p. 454). Deve ser um provocador da discussão; deve respeitar a fala das crianças; deve inserir-se na roda, estar disposto ao diálogo ao mesmo tempo que não deve ser aquele que tudo sabe; deve ser aquele que está mais preocupado com a pergunta do que com a resposta. Deve buscar a reflexão constante, comprometer-se com a investigação.

Contudo, esse tipo de busca não é comum a todos. Alguns docentes não conseguem conviver com essa inquietação que o projeto cria. Com as dúvidas que ele gera, com a divisão dos espaços na sala de aula, com a busca constante de respostas. Com o grande esforço intelectual que suscita, alguns ficaram no meio do caminho. Sob esse aspecto os que continuam são unânimes: há também uma sensação de que a prática filosófica é sempre uma prática do recomeçar. Nem todos resistem a essa prática. Alguns preferem a cômoda prática da disseminação vertical do saber, onde sua autoridade não é questionada, fundamentados na falta de objetividade da filosofia e de sua prática. Essa resistência se faz com mais força nos professores com um maior tempo de carreira, onde a prática da educação reprodutivista está mais sedimentada. Onde a formação teve ênfase na forja de uma identidade docente necessariamente detentora do saber para fazer-se competente. Uma coisa é certa: para praticar filosofia com crianças é preciso estar disposto a tal, pois essa prática não pode ser imposta sob a pena do fracasso. A chave para o sucesso de sua universalização, na minha leitura pessoal, está em dois eixos: na renovação natural do atual quadro e na colheita de resultados favoráveis da geração da educação para o pensar.

\section{O significado do projeto para as crianças}

Acredito no projeto Filosofia na Escola enquanto meio de reflexão da prática pedagógica e de formação de alunos mais críticos. Os alunos realmente desenvolvem-se ao longo deste de maneira singular. As primeiras falas dos educandos dentro da prática filosófica não são suas, são reproduções daquilo que sempre escutaram: "A escola é importante, pois pode nos dar um futuro melhor". Essa parece uma fala nossa e de seus pais apenas repetida pelos alunos, sem nenhuma elaboração própria como outros exemplos: "Boneca é coisa de menina porque é. Homem que é homem não brinca de boneca".

Inicialmente não é raro responderem apenas para participar, falarem esses chavões que escutam ao longo de suas trajetórias, mas com o decurso da prática filosófica parece-me que algo passa a mudar, primeiro os alunos procuram em nossas perguntas e reações as respostas que queremos ouvir ao invés de responder qualquer coisa, dependendo da expressão encontrada em nossos rostos falam ou se calam para nos agradar. Ao longo da insistência de nossos questionamentos parece que essa fala para o agradar também se modifica transformando-se em algo que eu chamaria de "reflexão própria". Uma imagem muito viva do projeto, para mim, foi a primeira vez que vi um aluno travar diante de uma pergunta. Não me lembro o tema da oficina. Lembro-me que a professora lançou uma pergunta $e$ o aluno a respondeu, ela questionou sua resposta e ele novamente respondeu, ela 
continuou a questionar e ele a responder até a hora em que ele parou, fixou o olhar por alguns minutos no nada e deu uma resposta sua para a pergunta, embasada em argumentos próprios e não em falas de outrem. Esse olhar para o nada e esse parar para refletir antes de responder algo que fugia do senso comum, ficou, para mim, como imagem marcante do projeto.

Uma afirmação que posso fazer é a de que o projeto mudou minha relação com as crianças. Passei realmente a ouvi-las, a escutá-las mais, a percebê-las como seres capazes de produções elaboradas e complexas. Antes do projeto minha atitude em relação às crianças, na tentativa de formação destas, era mais de incutir-lhes valores que eu achava necessários para o seu desenvolvimento saudável: o gosto pelo estudo, o trabalho com conteúdos que desenvolvessem o raciocínio, o respeito ao outro, mas nada tão ligado à libertação de um pensamento de outros $e$ à formação de sua própria produção. Através do projeto aprendi a escutar os alunos e a admirar o que falam e a tentar entender a lógica que utilizam. As falas dos alunos da professora Marli Abud, crianças da $3^{\text {a }}$ série do ensino fundamental, com 9 anos de idade, em uma oficina mediada por nós duas, sobre o pensamento me fizeram ficar pensando sobre essa lógica e sobre a sua rica produção durante muito tempo :

- O pensamento também leva a fazer coisas ruins como roubar, matar. Para roubar um banco tem que pensar muito antes.

- O pensamento faz a guerra.

- O pensamento faz coisas boas. Meu pai pensa na casa primeiro, depois desenha. E depois faz a casa. Ele usa o pensamento pra isso.

- O pensamento faz lógica.

- O que é lógica? (mediador)

- Lógica é pensar um caso para tentar resolver.

- A árvore não pensa porque ela não tem cérebro.

- Ela [a árvore] não pensa como a gente, mas pensa de um modo diferente. $A$ árvore pensa, se não pensasse não poderia fazer tantas coisas boas como tirar o gás carbônico, dar oxigênio, produzir frutos. Quem não pensa não pode fazer tudo isso.

- O meu cachorro pensa porque quando ele está com fome e pega a vasilha dele leva para minha mãe.

Penso ser esse um grande sentido do projeto para as crianças: o respeito ao seu pensar, à sua identidade, à sua construção e elaboração pessoal. Sua inserção enquanto sujeito do processo de aprendizagem. A divisão do espaço escolar, 
refletir e discutir valores pertencentes a esse espaço e até mesmo rejeitar alguns desses valores que julguem incongruentes com todo esse processo:

A filosofia na escola primária fornece um espaço que possibilita às crianças refletirem sobre seus valores, assim como sobre suas açôes. Graças a essas reflexões, as crianças podem começar a rejeitar valores que não estão à altura dos seus padrões e de guardarem aqueles que estão.

A filosofia oferece um espaço no qual os valores podem ser submetidos à crítica. Esta é, talvez, a principal razão para sua exclusão, até agora, da sala de aula da escola primária, e uma razão fundamental para que seja agora, finalmente incluída. (Lipman, 1995, p.41)

Assim estaríamos efetivamente trabalhando para a formação de seres autônomos, capazes de tomar decisões pautadas na elaboração do pensar, na escolha consciente baseada na compreensão dos significados do que está posto e do que está subentendido, baseado numa leitura crítica da realidade e não apenas da aceitação passiva desta.

Não compartilho com a opinião de alguns companheiros que afirmam que as crianças têm sido sujeitos passivos dentro do projeto. Vejo-as optando pelo projeto, discutindo, criticando, não é ainda uma adesão maciça, contudo vem crescendo ao longo do trabalho. Elas participam, as que não querem falar para o grande grupo comentam em pequenos grupos. Estão construindo esse processo, que é lento, precisa de tempo e dedicação de todos, mas os progressos são muitos. A prática das oficinas filosóficas em nossa escola tem fortalecido a participação das crianças no quotidiano pedagógico. Elas têm inserido suas vozes nas atividades da escola, têm proposto temas a serem discutidos, têm criticado as atividades que julgam não qualitativas, têm reivindicado mais espaços. Não se percebia tais práticas no contexto escolar até então.

As oficinas propiciam aos alunos um falar ao qual normalmente não estão acostumados, uma fala questionadora, voltada para a problematização e não para a resposta em si, uma fala que não necessariamente se dê entre o professor e o aluno, mas que tem acontecido cada vez mais entre aluno/aluno, propicia um cultivo atencioso da prática do pensar.

Os alunos vivenciam uma dinâmica diferente de organização, uma nova dinâmica pedagógica, prática muito rica, onde brincamos com vários tipos de pretextos para realizar as oficinas em sala de aula. Brincamos com o lúdico, com textos, piadas, desenhos, dinamizamos o espaço, ampliamos as possibilidades, o que enriquece o processo. Também nos deparamos com muitas dificuldades como o grande número de alunos em sala de aula, a falta de alguns recursos que poderiam enriquecer as oficinas, o silêncio de alguns, a fala simultânea de outros, dificuldades que acredito fazerem parte do processo.

Há uma grande riqueza de material para se trabalhar nas oficinas do pensar, uma infinidade de situações e de questões a serem colocadas não apenas por nós, mas 
também pelas crianças. Essa é a grande riqueza do projeto, que tem como finalidade não só o trabalho com os alunos, mas o trabalho de nós, mediadores e professores, em relação ao nosso próprio pensar, às nossas questões e à maneira como lidamos como o nosso pensamento e com o pensamento das crianças. Será que problematizamos nosso próprio pensar? Nossa prática, nossa ação é incansavelmente problematizada, alterada, revista, criamos as mais diversas alternativas para o desenvolvimento do projeto, para as oficinas com as crianças, mas não buscamos alternativas para problematizar a nós mesmos. Não falo da reflexão que há nas reuniões sobre a ação, falo de planejar oficinas que favoreçam esse problematizar a si mesmo, o seu próprio pensar, algo que fuja do mero relato, por vezes terapêutico, ou do problematizar de alguns sobre a fala de outros. Penso que tem faltado mais coragem na experimentação de novas vivências na exploração da ludicidade inerente ao universo infantil. Acredito que os mediadores, estudantes da UnB, podem contribuir muito nesse sentido à escola, pesquisando alternativas de vivência como atividade de extensão, ali mesmo onde a universidade produz conhecimentos em conjunto com a escola, enriquecendo todos os participantes do projeto.

\section{Considerações finais}

Praticar filosofia com crianças é um grande desafio, visto que não existem fórmulas para esse trabalho, que é forjado na construção coletiva, na aceitação do repto, na busca de caminhos. Penso que o grupo caminha e que hoje já conseguimos visualizar algumas respostas às tantas questões que nos vêm à mente. Outras continuam embaralhando-se, mas também acho natural dentro do caminhar que nos percamos um pouco. Seria preocupante se tivéssemos apenas certezas. Sinto que o grupo tem muitas questões: De que modo fazer alguns alunos se interessarem? Como desconstruir essa enormidade de conceitos e pensamentos prontos, introjetados durante anos? Como não conduzir pensamentos? Como não impor nossa ideologia nesse espaço? Não é trabalho fácil. Não existem respostas imediatas. Temos procurado pensar nestas questões e buscado alternativas $e$ experimentações coletivas para elas. Estamos trabalhando com a dimensão humana, e para essa não existem efeitos imediatos. Um caminho viável para essa busca é a formação continuada de professores, a manutenção da convivência entre os diversos sujeitos do projeto e a troca cada vez maior entre eles. Estudantes e professores em constante contato, trabalhando em conjunto na investigação $e$ experimentação das possibilidades.

O projeto Filosofia na Escola tem nos ensinado a ouvir vozes que antes não se pronunciavam. Tem nos ensinado a questionar. Tem desafiado nossas potencialidades. Tem nos levado ao crescimento, ainda que alguns não visualizem isso. Não concordo com a colocação de que parece que os professores só conseguem participar do projeto como reprodutores de técnicas criadas por outros. Tenho visto em muitos uma profunda mudança de atitude, uma participação efetiva, a discussão de suas atitudes e de suas práticas, antes impensáveis de entrar em discussão. A tentativa de modificar as oficinas, o planejamento de oficinas para outras aulas que não as de filosofia, uma mudança de postura, uma profunda 
inquietação. São relatos que escapam a quem está fora da rotina da escola, visíveis a quem está inserido nela e penso que aos seus alunos também.

Temos buscado resolver o hiato pedagógico que se estabeleceu entre a prática da atitude filosófica de busca do pensar e os outros momentos da escola. Temos procurado alternativas para resolver a ruptura existente na prática dos professores do projeto e demais professores da escola. Temos procurado expandir a discussão, ampliar o espaço do projeto dentro da escola. Assumiremos agora formalmente a prática da Filosofia como compromisso inserido no Projeto Político Pedagógico da Escola. Não há elementos suficientes para que façamos afirmações, estamos ainda buscando, talvez sempre estejamos buscando. Essa é uma configuração inerente ao projeto: a busca. Parece-me que essa atitude do investigar, intrínseca ao projeto, nos remete a um eterno retorno, a ponto de partida. Vejo que partilhamos um sentimento de inquietação, percebo esse sentimento como combustível do projeto, como o que nos leva a pensar, a buscar e a querer nos identificar enquanto sujeitos, forjando e sendo forjados numa relação de constituição de nós mesmos e de nossa própria prática.

\section{Referências}

Currículo da Educação Básica das Escolas Públicas do Distrito Federal: ensino fundamental $1^{\mathrm{a}}$ a $4^{\mathrm{a}}$ séries. $2^{\mathrm{a}}$ edição. Brasília: Secretaria de Estado de Educação, 2002.

Koan , Walter Omar. Infância. Entre educação e Filosofia. Belo Horizonte: Autêntica, 2003.

Leal , Bernadina. "Filosofia com crianças: uma incursão" In: Filosofia na escola pública. Vol V, Coleção Filosofia na Escola. Petrópolis: Vozes, 2000.

Lipman, Matthew. O Pensar na Educação. Trad. Port. Petrópolis, RJ: Vozes, 1995.

Waksman , Vera. "Quem é o professor de Filosofia?" In: Filosofia na escola pública. Vol V, Coleção Filosofia na Escola. Petrópolis: Vozes, 2000.

(1) Estudante do Curso de Pedagogia da UnB, professora das séries iniciais do ensino fundamental na Escola Classe 06 de Planaltina. (e-mail: patriciaperegrino@yahoo.com.br )

(2) A modulação é um documento oficial que define o número de funcionários de um estabelecimento de ensino. O critério usado para estabelecer esse quantitativo é o número de alunos que a escola atende.

(3) O currículo seguido pela escola é o Currículo da Educação Básica das Escolas Públicas do Distrito Federal vigente em versão experimental de 2000 a 2001 e em versão final a partir de 2002. Esse currículo, pela primeira vez, não é centrado em 
conteúdos a aplicar, mas em habilidades e competências que os alunos precisam desenvolver.

(4) Currículo da Educação Básica das Escolas Públicas do Distrito Federal: ensino fundamental $1^{\mathrm{a}}$ a $4^{\mathrm{a}}$ séries. $2^{\mathrm{a}}$ edição. Brasília: Secretaria de Estado de Educação, 2002 , p.13.

(5) Essa disciplina é ministrada para alunos do curso de Pedagogia no seu primeiro semestre e tem como objetivo propiciar aos alunos um maior conhecimento da Universisade, do curso, de suas áreas de atuação. Foi através dessa rica proposta que conheci o projeto pela apresentação o professor Álvaro Ribeiro.

(6) Fala de Daliane do Nascimento Martins de oito anos. Aluna da professora Geraldina Elias Bonfim, $2^{\mathrm{a}}$ série $\mathrm{D}$, no desenvolvimento de oficina de filosofia do projeto Filosofia na Escola que tinha como tema pensamento.

(7) Fala de Joyce Lorrane Gomes da Silva de nove anos. Aluna da professora Geraldina, $2^{\mathrm{a}}$ série $\mathrm{D}$, no desenvolvimento de oficina de filosofia do projeto Filosofia na Escola que tinha como tema autoconhecimento. 